\title{
Pulmonary Fibroplasia in Newborn Babies Treated with Oxygen and Artificial Ventilation
}

\author{
C. K. BANERJEE, ${ }^{\star}$ D. J. GIRLING, $†$ and J. S. WIGGLESWORTH \\ From the Neonatal Research Unit, Institute of Child Health, Hammersmith Hospital, London
}

\begin{abstract}
Banerjee, C. K., Girling, D. J., and Wigglesworth, J. S. (1972). Archives of Disease in Childhood, 47,509. Pulmonary fibroplasia in newborn babies treated with oxygen and artificial ventilation. A retrospective clinicopathological study was carried out on newborn babies who had died over a 5-year period, had received oxygen therapy, and had lived for 48 hours or longer. 23 of 81 babies had pulmonary fibroplasia at necropsy. Prolonged therapy in oxygen concentrations above $60 \%$ and prolonged artificial ventilation were associated with the development of pulmonary fibroplasia. All babies developing pulmonary fibroplasia had been treated in over $60 \%$ oxygen for at least 46 hours and the condition was invariably present in those who had over $60 \%$ oxygen for more than 123 hours or above $80 \%$ oxygen for more than 105 hours. The relation of pulmonary fibroplasia to mechanical ventilation was less constant.

Hyaline membrane disease was associated with the development of fibroplasia in babies who lived for 3 days or longer, and the most severe histological changes were almost always associated with HMD. There was no correlation between gestational age and development of pulmonary fibroplasia.

It is concluded that oxygen toxicity was probably the most important cause of pulmonary fibroplasia in the babies studied, though some histological features may be more closely related to artificial ventilation. The implications of these findings for oxygen and ventilator therapy in the newborn are discussed.
\end{abstract}

The condition known variously as pulmonary fibroplasia, bronchopulmonary dysplasia, or ventilator lung has been described in patients of all ages treated with oxygen and artificial ventilation (Robertson, Tunell, and Rudhe, 1964; Hawker, Reynolds, and Taghizadeh, 1967; Northway, Rosan, and Porter, 1967; Nash, Blennerhassett, and Pontoppidan, 1967; Becker and Koppe, 1969; Pusey, Macpherson, and Chernick, 1969).

The lungs of the newborn infant with respiratory distress who dies after being maintained for a week or more on the ventilator in an oxygenenriched environment may present a striking appearance at necropsy. They are bulky and overweight and appear consolidated on section. Histological examination shows hyperplasia and squamous metaplasia of the bronchial and bronch-

\footnotetext{
Received 21 January 1972.

^Present address: Department of Pathology, Postgraduate Medical Institute, Chandigarh, India.

tPresent address: M.R.C. Tuberculosis and Chest Diseases Unit, Brompton Hospital, London.
}

iolar epithelium, muscle hypertrophy of the bronchial walls, fibroblast proliferation, and increased reticulin throughout the lobular connective tissue, and thickening of alveolar walls by proliferation of alveolar lining cells.

At least three causes for the development of pulmonary fibroplasia in such babies have been suggested: that it is the result of oxygen toxicity, that it is due to mechanical damage caused by artificial ventilation, and that it represents a late repair stage of severe hyaline membrane disease in babies kept alive by artificial ventilation after they would otherwise have died.

We have carried out a retrospective clinicopathological study of the pathogenesis of pulmonary fibroplasia in newborn babies to try and determine the relative importance of the occurrence of hyaline membrane disease, the concentration and duration of oxygen therapy, and the duration of artificial ventilation.

Most reports on pulmonary fibroplasia in the newborn have described babies who have received 
long periods of oxygen therapy and artificial ventilation. This series consists predominantly of early neonatal deaths and is therefore mainly concerned with the early changes of pulmonary fibroplasia.

\section{Babies Studied and Methods of Investigation}

Patients. The series included all babies who had died in the Neonatal Unit from November 1965 to October 1970 but who had lived for 48 hours or more, and who received oxygen therapy. There were 81 babies in the study; their gestational age at birth ranged from 24 to 42 weeks; 64 received artificial ventilation; at necropsy 39 were found to have hyaline membrane disease, and 23 unequivocal changes of pulmonary fibroplasia.

Oxygen therapy. During oxygen treatment all babies had their inspired oxygen concentrations recorded at hourly intervals using a Beckman paramagnetic oxygen analyser. Their oxygen therapy was monitored by blood gas estimations made on arterial blood, and an attempt was made to keep arterial $\mathrm{Po}_{2}$ between 60 and $90 \mathrm{mmHg}$ in immature babies and over $60 \mathrm{mmHg}$ in mature ones. The number of hours that each baby spent breathing, respectively, less than $60 \% \mathrm{O}_{2}$, between 60 and $80 \% \mathrm{O}_{2}$, and over $80 \% \mathrm{O}_{2}$, was recorded.

Artificial ventilation. Babies requiring artificial ventilation were connected to a pressure-limited intermittent positive pressure ventilator delivering an approximately square-wave pressure profile (Grausz, Watt, and Becket, 1967). They were ventilated with humidified oxygen or oxygen and air mixtures, and the ventilator rate, pressure, and inspiratory to expiratory ratio were adjusted to keep arterial $\mathrm{PcO}_{2}$ within normal limits. The indications for arterial ventilation were (a) total apnoea not responding to routine resuscitation, and (b) respiratory failure which was progressive in spite of attempts to correct acidosis, electrolyte disturbances, hypoglycaemia, or other intercurrent abnormalities. The severity of respiratory failure was assessed by a combination of clinical observation and arterial blood gas estimations. The total number of hours that each baby spent on the ventilator was recorded.

Pulmonary histology. A full necropsy had been performed on all cases and material from all major organs fixed in formal saline and processed in routine fashion. Four lung sections from the major lobes stained with haemotoxylin and eosin were available for assessment in each case. Further sections were stained with Weigert's elastic van Gieson stain, Gordon and Sweets reticulin stain, and other stains such as periodic acid-Schiff and Martius Scarlet Blue, as indicated. For the purpose of this study the sections were reviewed without knowledge of the clinical history or details of oxygen and ventilator therapy. The severity of pulmonary fibroplasia was assessed on a histological grading system scoring 0 to 3 separately for the degree of (a) bronchial epithelial hyperplasia and squamous metaplasia, (b) fibroblast proliferation round bronchioles and alveolar ducts, and (c) thickening and fibroblast proliferation within alveolar septa. The maximum score was thus 9 . The sections were reviewed for a second time without reference to the original findings after an interval of a month. The majority, in which the assessment did not differ significantly on different occasions, were classified as normal or as mild (1-2), moderate (3-4), or severe (5-9) pulmonary fibroplasia. In 10 cases of hyaline membrane disease (HMD), dying mostly at 2 to 3 days of age, it proved impossible to be certain whether the changes seen were part of the normal repair process or the earliest stage of pulmonary fibroplasia, and they were assessed differently on different occasions. These were not classified as having pulmonary fibroplasia and have been included within the normal group for statistical analysis.

The grading of severity was regarded as approximate only, since infants had survived for varying lengths of time and the lesions were thus seen at different stages of development. It was by no means certain that a lung with fully developed changes graded as 'moderate' at 2 months of age would have been similarly graded had the baby died earlier when the lesions were in the developing phase.

\section{Results}

Histology. Unequivocal changes of pulmonary fibroplasia were seen in lungs from 23 of the 81 babies. The earliest changes recognizable as pulmonary fibroplasia were seen in the lungs of one infant dying at 55 hours, and in 8 who died at under 5 days of age. In addition to the changes of HMD seen in 5 of the 8 , there was hyperplasia and early squamous metaplasia of bronchial and bronchiolar epithelium and a broad zone of proliferating fibroblasts round respiratory bronchioles and alveolar ducts (Fig. 1). Fibroblast proliferation extended into the connective tissue round and between the alveoli. In cases with HMD the changes round the respiratory bronchioles were usually the most prominent.

The earliest age at which severe changes throughout the lung were seen was 79 hours (Fig. 2). Between 5 days and 2 weeks the distortion produced by the fibroplasia became more obvious and squamous metaplasia of bronchial and bronchiolar epithelium was more pronounced (Fig. 3 and 4). Hyaline membranes were slow to resolve, being present in cases dying at up to 8 days of age. In areas where interstitial fibroplasia was pronounced the air-spaces appeared to have reverted to an immature structure with a continuous cuboidal epithelial lining and loss of blood-air barriers (Fig. 5).

In babies with pulmonary fibroplasia who had 
Fig. 1.-Case 80, aged 67 hours $(H$. and $E . \times 86)$. Note bronchial epithelial hyperplasia (top left) and fibroblast proliferation round respiratory bronchiole (lower right).

lived for 2 weeks or more the walls of terminal and respiratory bronchioles showed considerable increase in muscle and elastic tissue (Fig. 6 and 7). A marked increase in reticulin could be shown in the connective tissue round and between the alveoli as well as in the thickened bronchiolar walls, and there was a slight increase in collagen in some areas
(Fig. 8). Additional features seen included loculated areas of inspissated secretions, and sometimes evidence of superimposed pneumonia or focal pneumonitis.

Clinicopathological correlations. Table I shows the clinical information and histological

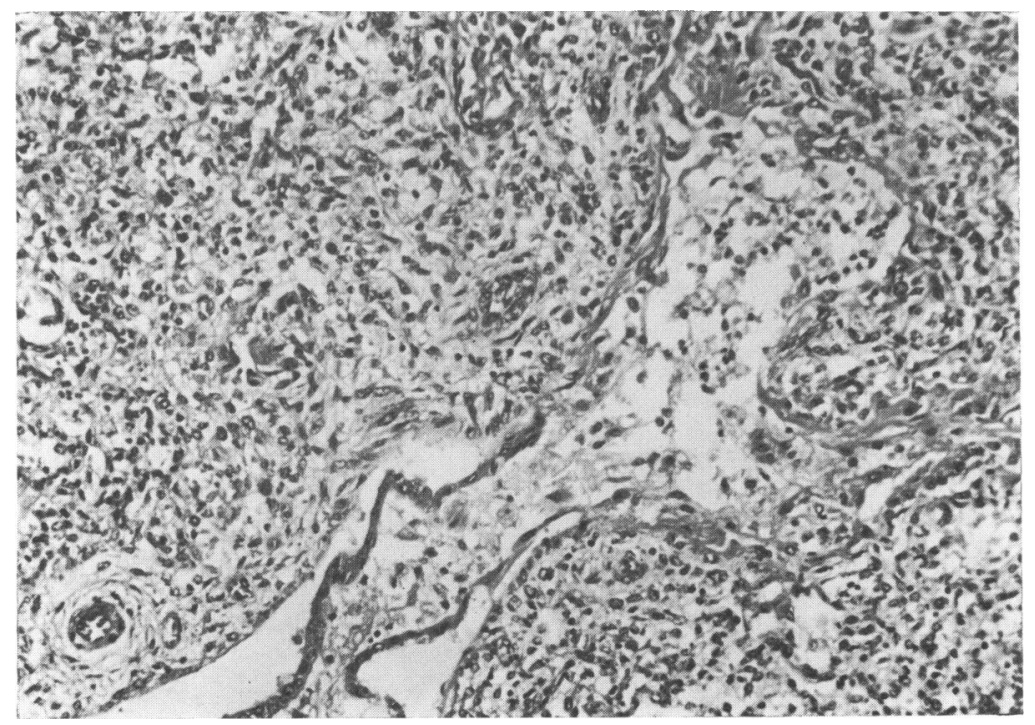

FIG. 2.-Case 59, aged 79 hours $(H$. and E. $\times 86)$. Extensive fibroblast proliferation round respiratory bronchioles. 
TABLE I

Details of $\mathrm{O}_{2}$ and Ventilator Therapy in Infants with Pulmonary Fibroplasia

\begin{tabular}{|c|c|c|c|c|c|c|c|c|c|c|c|}
\hline $\begin{array}{l}\text { Case } \\
\text { No. }\end{array}$ & Sex & $\begin{array}{l}\text { Gestation } \\
\text { (wk) }\end{array}$ & $\begin{array}{l}\text { Birth- } \\
\text { weight } \\
\text { (g) }\end{array}$ & $\begin{array}{c}\text { Age } \\
\text { at } \\
\text { Death }\end{array}$ & $\begin{array}{c}\text { Duration } \\
\text { Mechanical } \\
\text { Ventilation } \\
\text { (hr) }\end{array}$ & $\begin{array}{c}\text { Duration } \\
\mathrm{O}_{2} \\
\text { Therapy } \\
\text { (hr) }\end{array}$ & $\begin{aligned} & \mathrm{O}_{2} \\
> & 80 \% \\
& (\mathrm{hr})\end{aligned}$ & $\begin{array}{c}\mathrm{O}_{2} \\
60-80 \% \\
(\mathrm{hr})\end{array}$ & $\begin{array}{c}\mathrm{O}_{2} \\
<60 \% \\
(\mathrm{hr})\end{array}$ & HMD & $\begin{array}{l}\text { Histological } \\
\text { Findings }\end{array}$ \\
\hline $\begin{array}{r}7 \\
12 \\
17 \\
20 \\
22 \\
23 \\
25 \\
29 \\
34 \\
39 \\
40 \\
41 \\
50 \\
51 \\
52 \\
53 \\
55 \\
56 \\
58 \\
59 \\
62 \\
80 \\
81\end{array}$ & $\begin{array}{l}F \\
M \\
F \\
F \\
M \\
M \\
M \\
M \\
M \\
M \\
F \\
M \\
M \\
M \\
M \\
M \\
M \\
F \\
M \\
M \\
F \\
F \\
M\end{array}$ & $\begin{array}{l}38 \\
32 \\
32 \\
32 \\
27 \\
30 \\
32 \\
33 \\
42 \\
33 \\
29 \\
30 \\
28 \\
29 \\
36 \\
33 \\
36 \\
42 \\
28 \\
34 \\
26 \\
36 \\
41\end{array}$ & $\begin{array}{r}3090 \\
1500 \\
1620 \\
2020 \\
1020 \\
1640 \\
1920 \\
2120 \\
2100 \\
2230 \\
1200 \\
1230 \\
1100 \\
1360 \\
2400 \\
1460 \\
2360 \\
3100 \\
910 \\
2560 \\
1280 \\
2000 \\
2930\end{array}$ & $\begin{array}{c}20 \mathrm{dy} \\
193 \\
153 \\
39 \mathrm{dy} \\
449 \\
60 \mathrm{dy} \\
139 \\
106 \\
107 \\
54 \mathrm{dy} \\
179 \\
145 \\
93 \\
187 \\
100 \\
396 \\
113 \\
108 \\
137 \\
79 \\
55 \dagger \\
67 \dagger \\
194\end{array}$ & $\begin{array}{c}197 \\
158 \\
70 \\
36 \mathrm{dy} \\
180 \\
272 \\
134 \\
21 \\
95 \\
41 \mathrm{dy} \\
128 \\
120 \\
77 \\
154 \\
92 \\
385 \\
118 \\
7 \\
135 \\
81 \\
46 \\
0 \\
162\end{array}$ & $\begin{array}{c}420 \\
192 \\
152 \\
39 \mathrm{dy} \\
432 \\
60 \mathrm{dy} \\
134 \\
106 \\
107 \\
54 \mathrm{dy} \\
179 \\
145 \\
93 \\
187 \\
100 \\
396 \\
133 \\
106 \\
137 \\
79 \\
54 \\
66 \\
194\end{array}$ & $\begin{array}{c}183 \\
137 \\
118 \\
39 \text { dy } \\
424 \\
43 \text { dy } \\
134 \\
17 \\
99 \\
54 \text { dy } \\
173 \\
21 \\
80 \\
61 \\
78 \\
342 \\
133 \\
52 \\
22 \\
69 \\
54 \\
23 \\
109\end{array}$ & $\begin{array}{r}85 \\
35 \\
25 \\
0 \\
8 \\
9 \text { dy } \\
0 \\
69 \\
8 \\
0 \\
6 \\
30 \\
0 \\
11 \\
18 \\
48 \\
0 \\
0 \\
60 \\
10 \\
0 \\
22 \\
42\end{array}$ & $\begin{array}{r}152 \\
20 \\
9 \\
0 \\
0 \\
8 \mathrm{dy} \\
0 \\
20 \\
0 \\
0 \\
0 \\
94 \\
13 \\
85 \\
4 \\
6 \\
0 \\
54 \\
55 \\
0 \\
0 \\
21 \\
43\end{array}$ & $\begin{array}{l}\text { No } \\
\text { Yes } \\
\text { Yes } \\
\text { Yes } ¥ \\
\text { No } \\
\text { No } \\
\text { Yes } \\
\text { Yes } \\
\text { Yes } \\
\text { No } \\
\text { Yes } \\
\text { Yes } \\
\text { Yes } \\
\text { No } \\
\text { Yes } \\
\text { Yes } \\
\text { Yes } \\
\text { No } \\
\text { No } \\
\text { No } \\
\text { No } \\
\text { Yes } \\
\text { Yes }\end{array}$ & $\begin{array}{l}\text { Moderate } \\
\text { Severe } \\
\text { Mild } \\
\text { Severe } \\
\text { Moderate } \\
\text { Mild } \\
\text { Severe } \\
\text { Moderate } \\
\text { Moderate } \\
\text { Moderate } \\
\text { Severe } \\
\text { Severe } \\
\text { Moderate } \\
\text { Mild } \\
\text { Severe } \\
\text { Severe } \\
\text { Moderate } \\
\text { Moderate } \\
\text { Moderate } \\
\text { Severe } \\
\text { Mild } \\
\text { Moderate } \\
\text { Severe }\end{array}$ \\
\hline
\end{tabular}

^Age at death in hours unless days stated.

†Babies who died under 3 days of age.

¥HMD diagnosed on severity of bronchiolar lesions and clinical picture in early stage of illness.

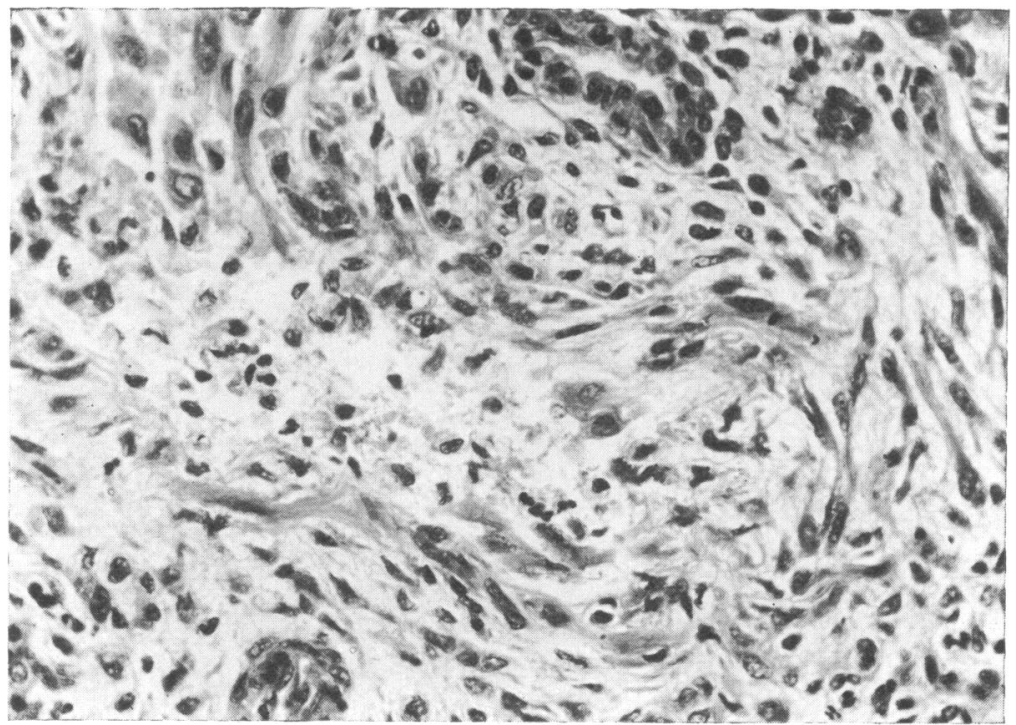

Fig. 3.-Case 40, aged 7 days $(H$. and $E . \times 215)$. Fibroblast proliferation round respiratory bronchiole is well developed. 


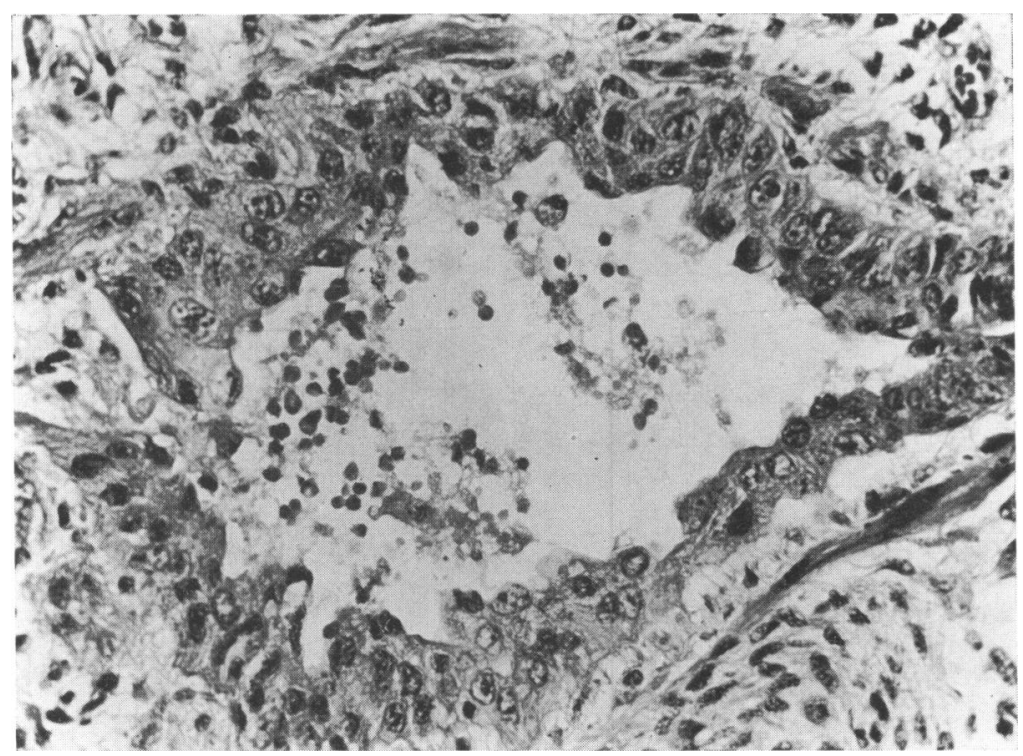

Fig. 4.-Case 40, aged 7 days $(H$. and E. $\times 215)$. Hyperplasia and squamous metaplasia of bronchial epithelium.

grading for the 23 babies with unequivocal pulmonary fibroplasia. These babies were compared with the rest in respect of gestation, incidence of $H M D$, duration of artificial ventilation, and duration of treatment with over $60 \%$ oxygen. As 21 of the 23 babies with pulmonary fibroplasia had lived for 72 hours or more, similar comparisons were made between these babies and the 21 without pulmonary fibroplasia who had survived for over 72 hours (details of latter group shown in Table II).

TABLE II

Details of $\mathrm{O}_{2}$ and Ventilator Therapy in Infants Who Died at 3 Days of Age or More Without Changes of Pulmonary Fibroplasia

\begin{tabular}{|c|c|c|c|c|c|c|c|c|c|c|}
\hline $\begin{array}{l}\text { Case } \\
\text { No. }\end{array}$ & Sex & $\begin{array}{l}\text { Gestation } \\
\text { (wk) }\end{array}$ & $\begin{array}{l}\text { Birth- } \\
\text { weight } \\
\text { (g) }\end{array}$ & $\begin{array}{l}\text { Age at } \\
\text { Death* }\end{array}$ & $\begin{array}{c}\text { Duration } \\
\text { Mechanical } \\
\text { Ventilation } \\
\text { (hr) }\end{array}$ & $\begin{array}{c}\text { Duration } \\
\mathrm{O}_{2} \\
\text { Therapy } \\
\text { (hr) }\end{array}$ & $\begin{array}{c}\mathrm{O}_{2} \\
>80 \% \\
(\mathrm{hr})\end{array}$ & $\begin{array}{c}\mathrm{O}_{2} \\
60-80 \% \\
(\mathrm{hr})\end{array}$ & $\begin{array}{c}\mathrm{O}_{2} \\
<60 \% \\
(\mathrm{hr})\end{array}$ & HMD \\
\hline $\begin{array}{r}8 \\
9 \\
16 \\
21 \\
24 \\
30 \\
33 \\
37 \\
38 \\
42 \\
43 \\
46 \\
54 \\
57 \\
60 \\
61 \\
69 \\
70 \\
74 \\
75 \\
79\end{array}$ & 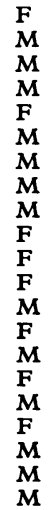 & $\begin{array}{l}24 \\
39 \\
38 \\
29 \\
26 \\
39 \\
37 \\
33 \\
40 \\
28 \\
36 \\
32 \\
32 \\
40 \\
30 \\
28 \\
30 \\
30 \\
34 \\
34 \\
33\end{array}$ & $\begin{array}{r}780 \\
2620 \\
2380 \\
1400 \\
780 \\
3240 \\
2660 \\
860 \\
3640 \\
1010 \\
3200 \\
1390 \\
2020 \\
3700 \\
1220 \\
980 \\
1910 \\
950 \\
1960 \\
2480 \\
2090\end{array}$ & $\begin{array}{c}101 \\
138 \\
114 \\
107 \\
121 \\
131 \\
91 \\
159 \\
168 \\
404 \\
78 \\
160 \\
146 \\
85 \\
30 \text { dy } \\
154 \\
89 \\
22 \text { dy } \\
174 \\
34 \text { dy } \\
72\end{array}$ & $\begin{array}{r}16 \\
0 \\
41 \\
4 \\
0 \\
103 \\
53 \\
72 \\
0 \\
162 \\
30 \\
0 \\
74 \\
20 \\
16 \\
30 \\
76 \\
160 \\
75 \\
0 \\
23\end{array}$ & $\begin{array}{r}101 \\
138 \\
102 \\
107 \\
121 \\
131 \\
91 \\
152 \\
168 \\
400 \\
78 \\
160 \\
144 \\
85 \\
187 \\
154 \\
84 \\
331 \\
123 \\
354 \\
72\end{array}$ & $\begin{array}{r}1 \\
2 \\
59 \\
103 \\
0 \\
71 \\
80 \\
1 \\
88 \\
0 \\
23 \\
1 \\
74 \\
17 \\
0 \\
1 \\
56 \\
0 \\
1 \\
1 \\
16\end{array}$ & $\begin{array}{r}0 \\
54 \\
43 \\
0 \\
7 \\
13 \\
10 \\
0 \\
35 \\
3 \\
34 \\
0 \\
12 \\
24 \\
0 \\
0 \\
24 \\
0 \\
0 \\
0 \\
33\end{array}$ & $\begin{array}{r}100 \\
82 \\
0 \\
4 \\
114 \\
47 \\
1 \\
151 \\
45 \\
397 \\
21 \\
159 \\
58 \\
44 \\
187 \\
153 \\
4 \\
331 \\
122 \\
353 \\
23\end{array}$ & $\begin{array}{l}\text { No } \\
\text { No } \\
\text { Yes } \\
\text { No } \\
\text { No } \\
\text { No } \\
\text { Yes } \\
\text { No } \\
\text { No } \\
\text { No } \\
\text { Yes } \\
\text { No } \\
\text { No } \\
\text { No } \\
\text { No } \\
\text { No } \\
\text { Yes } \\
\text { No } \\
\text { No } \\
\text { No } \\
\text { Yes }\end{array}$ \\
\hline
\end{tabular}

^Age at death in hours unless days stated. 


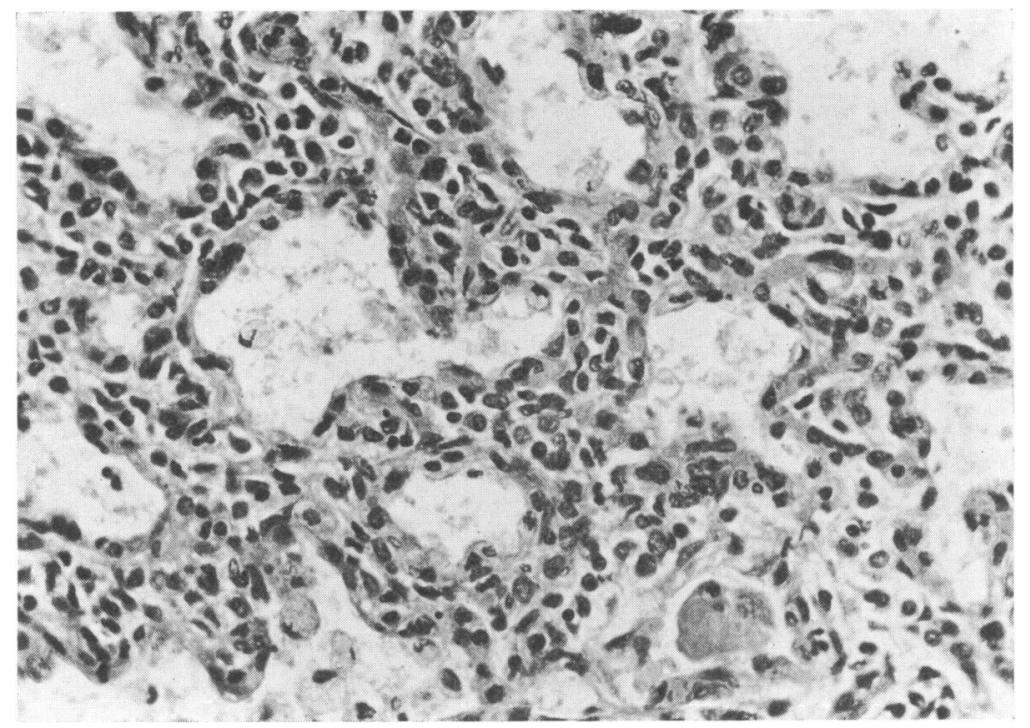

FIG. 5.-Case 40, aged 7 days $(H$. and $E . \times 215)$. Thick, cellular, alveolar septa with extensive cuboidal alveolar lining layer and few blood-air barriers (capillaries bulging into air-spaces).

Gestation. Gestational age did not differ between the 2 groups. Babies developed pulmonary fibroplasia at any gestation from 27 to 42 weeks, and there was no indication of any increased susceptibility to the condition with decreased gestation. There was no difference in these findings if babies dying at less than $\mathbf{7 2}$ hours were excluded.
Hyaline membrane disease. The incidence of HMD did not differ significantly between the groups of babies with and without pulmonary fibroplasia if all cases were included. If babies dying at less than 72 hours were excluded, HMD was more frequent in babies with pulmonary fibroplasia (13 of 21) than in those without (5 of

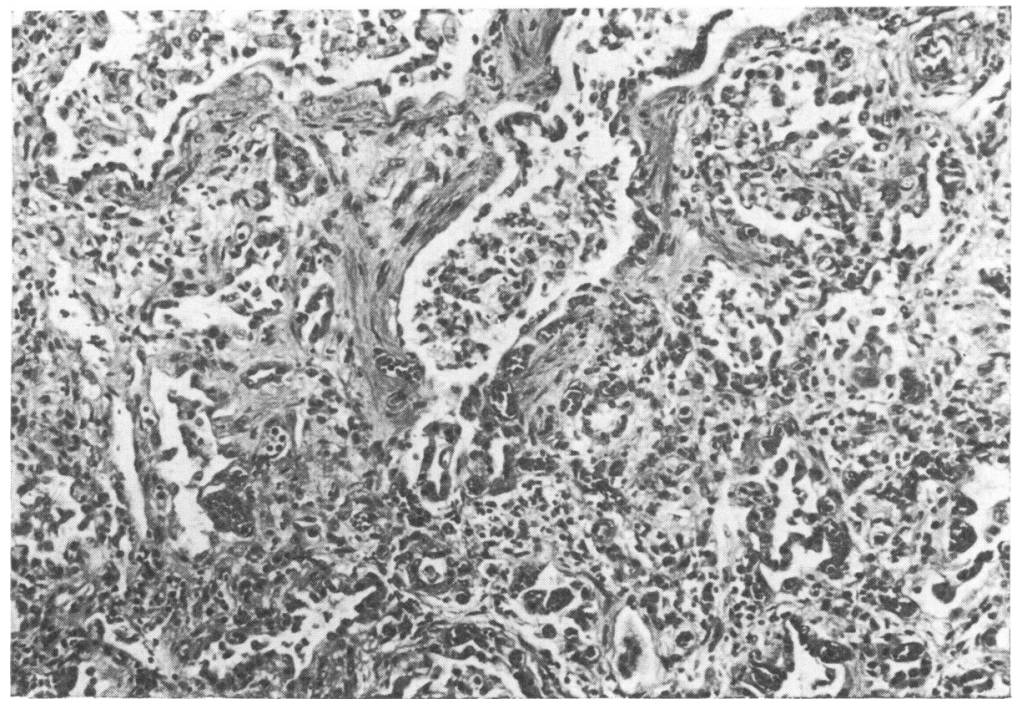

FIG. 6.-Case 39, aged 54 days $(H$. and $E . \times 86)$. Marked muscle hypertrophy within walls of respiratory bronchioles. 


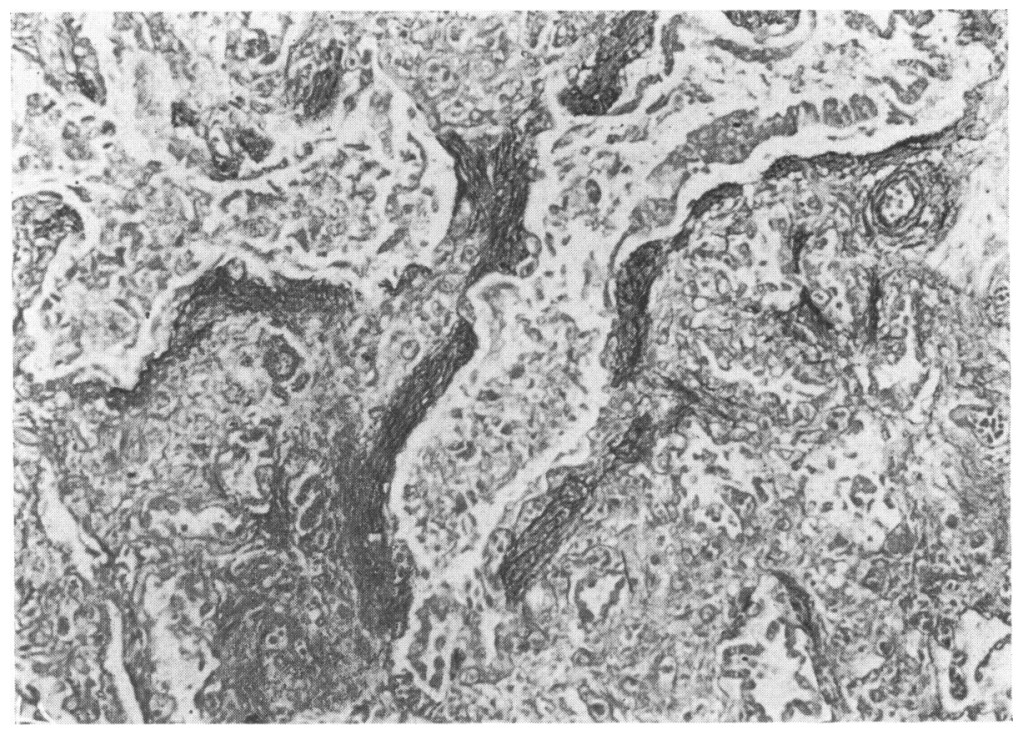

Fig. 7.-Case 39, aged 54 days. (Elastic van Gieson. $\times$ 86.) Adjacent section to that shown in Fig. 6 . Increased elastic tissue within walls of respiratory bronchioles.

21); $\chi^{2}=4 \cdot 76$ with Yates correction, $P=0.029$. Nearly all infants with severe changes of pulmonary fibroplasia had evidence of HMD.

Duration of artificial ventilation and treatment with over $60 \%$ oxygen. There was a significant difference in the duration of treatment with over $60 \%$ oxygen and with artificial ventilation between the 2 groups of babies irrespective of whether those dying at less than 72 hours were excluded or not (using student's ' $t$ ' test $P<0.001$ for each treatment). Fig. 9 shows the duration of treatment with over $60 \%$ oxygen plotted against the duration of artificial ventilation for babies

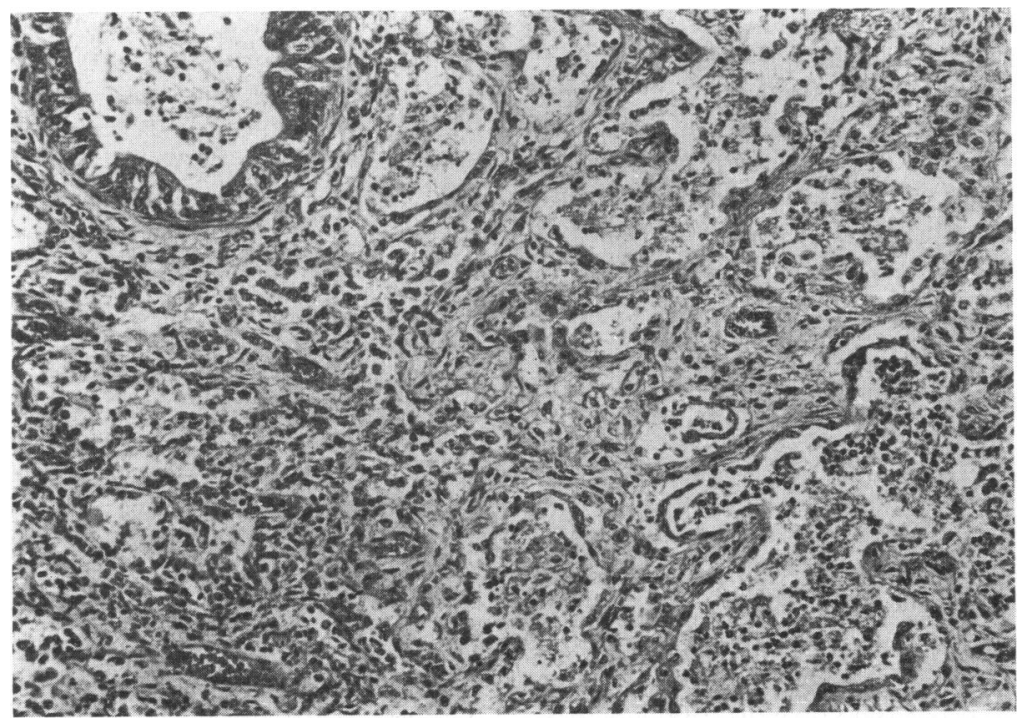

FIG. 8.-Case 20, aged 39 days (H. and E. 86). Fibrosis of alveolar septa. Note persistence of abnormal bronchial epithelium. 


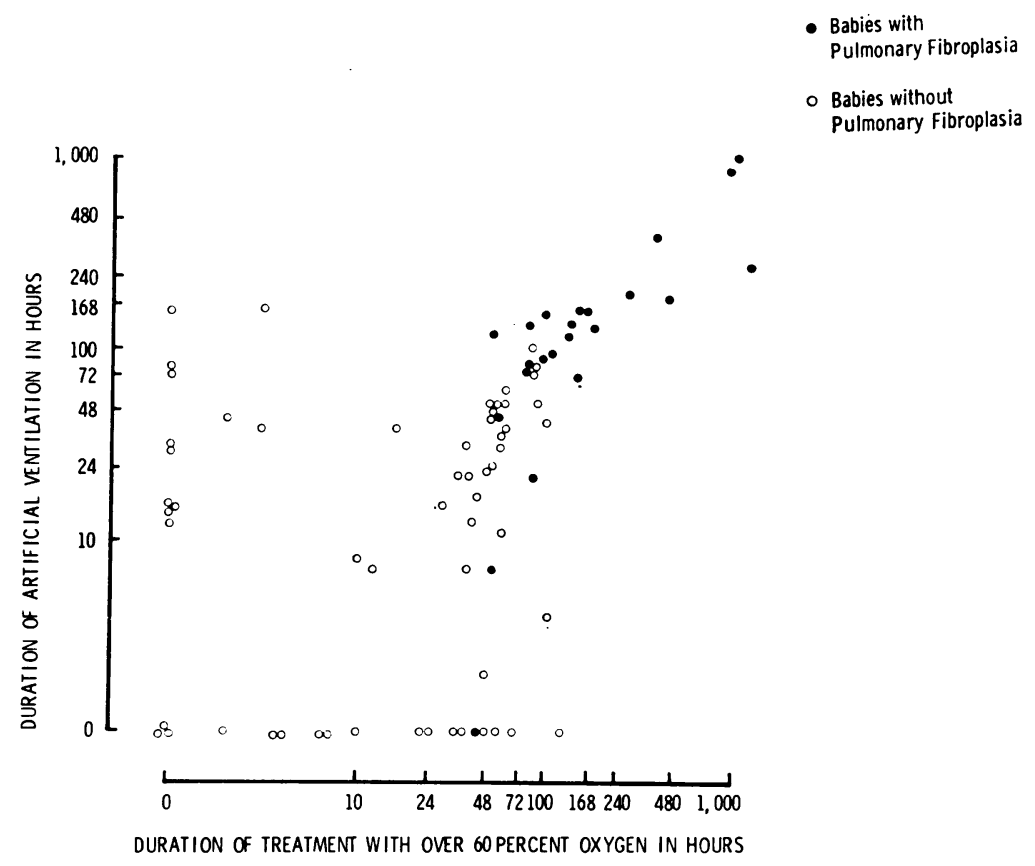

FIG. 9.-Lung histology plotted against duration of artificial ventilation and duration of treatment in over $60 \%$ oxygen (both axes on logarithmic scale).

with and without pulmonary fibroplasia. It can be seen that the babies most likely to develop pulmonary fibroplasia were those who had received both prolonged oxygen therapy and prolonged artificial ventilation. The durations of oxygen therapy and of artificial ventilation were analysed as covariables in respect of the production of pulmonary fibroplasia, but the 2 treatments could not be significantly distinguished from each other. This was thought simply to be due to the fact that the babies who received one treatment tended to be the same babies as those who received the other. However, no infant receiving less than 46 hours treatment with over $60 \%$ oxygen developed pulmonary fibroplasia, whereas 3 babies developed the condition after less than 24 hours ventilation. Moreover all infants treated with over $60 \%$ oxygen for more than 123 hours or with over $80 \%$ oxygen for more than 105 hours developed pulmonary fibroplasia, whereas 2 babies were ventilated for 160 hours (in less than $60 \%$ oxygen) without developing pulmonary fibroplasia. Prolonged treatment with high oxygen concentration was thus invariably associated with pulmonary fibroplasia whereas prolonged ventilation was not.
Treatment with less than $60 \%$ oxygen. $\stackrel{\mathbb{D}}{\mathscr{D}}$ Treatment with oxygen concentrations below $60 \% \stackrel{\vec{P}}{\vec{B}}$ was not associated with the development of pulmonary fibroplasia and many of the babies treated with over $60 \%$ oxygen for short periods had been treated with lower oxygen concentrations for periods of up to 2 weeks without developing it (e.g. Case 42, Table II).

\section{Discussion}

In this study of the pathogenesis of early pulmonary fibroplasia in newborn babies dying of respiratory failure we have shown significant associations with prolonged treatment with over $60 \%$ oxygen with prolonged ventilator therapy, of and (in babies dying at over 3 days of age) with $N$ hyaline membrane disease.

Oxygen toxicity and artificial ventilation. We found it difficult to separate the effects of oxygen toxicity and artificial ventilation simply because both forms of treatment were usually given concurrently. In view of the constant association between prolonged treatment with high 


\section{Pulmonary Fibroplasia in Newborn Babies Treated with Oxygen and Artificial Ventilation 517}

oxygen concentrations and pulmonary fibroplasia and the inconstant association between prolonged ventilation and pulmonary fibroplasia it seems probable that oxygen toxicity was the major factor. Even if oxygen toxicity is accepted as the major cause of pulmonary fibroplasia in this series one cannot rule out artificial ventilation as a contributory factor. Though deLemos et al. (1969) showed that artificial ventilation did not affect the development of early oxygen damage in the lungs of healthy lambs, Barnes et al. (1969) found that all 6 infants who required artificial ventilation for more than 6 months developed severely abnormal lung function, despite limitation of oxygen concentration to below $50 \%$ in 4 of them. The findings of Barnes et al. cannot of course be compared directly with those of the present study, as the time course of ventilation was so different and the impairment of lung function in the older infants was not correlated with any structural alterations. It is perhaps worthy of note that most of the severe cases of pulmonary fibroplasia in our series were seen within the first 2 years after the introduction of ventilator therapy to the Neonatal Unit and before problems in achieving adequate humidification had been overcome.

Relation of hyaline membrane disease to pulmonary fibroplasia. Difficulty in the interpretation of the relation of HMD to pulmonary fibroplasia arises on two counts. First, the development of HMD is the most frequent indication for prolonged oxygen and ventilator therapy in the newborn, and for this reason alone one would expect to find a correlation between HMD and any complications of these forms of treatment. Secondly, the development of hyaline membranes with oedema and haemorrhage is recognized as being a characteristic feature of the early or exudative phase of pulmonary oxygen toxicity in both adult man (Capers, 1961; Nash et al., 1967) and in monkeys (Robinson et al., 1967). Since the newborn human infant develops pulmonary hyaline membranes more readily than either adult man or most other animals, it would be surprising if he did not show this reaction as a feature of pulmonary oxygen toxicity. Indeed, it has even been suggested (Shanklin, 1969) that exposure to the normal atmosphere of $21 \%$ oxygen at birth is the cause of HMD in the preterm infant. In 2 infants of our series, pulmonary fibroplasia was associated with well-developed hyaline membranes despite a gestation of at least 41 weeks. Abnormal mechanical properties associated with loss of surfactant would not be expected at this stage of gestation.
If any of the newborn babies in this series died from the effects of acute pulmonary oxygen toxicity with exudative lung changes only, the diagnosis could not have been made by us at necropsy. Disregarding this possibility, there may still be some form of interaction between high inspired oxygen concentrations, mechanical ventilation, and HMD in producing the changes seen in the more gross forms of pulmonary fibroplasia. The muscle and elastic hypertrophy of the bronchiolar walls, and the masses of inspissated secretions, may well be the result of prolonged ventilation of a lung with abnormal mechanical properties. It is also possible that the normal repair phase of HMD may become exaggerated by exposure to a high inspired oxygen concentration.

Significance of structural changes. The immediate and long-term significance of the histological lesions seen at necropsy merit some consideration.

In a number of cases (those graded as severe) the structural damage to the lung due to pulmonary fibroplasia was severe enough to be regarded as adequate cause for continued respiratory failure and the major reason for the infant's death. In other cases the lesions were incidental findings at necropsy and it must be assumed that babies with similar lesions have survived.

The long-term effect on lung development and function of 'mild' or 'moderate' degrees of pulmonary fibroplasia is not easy to assess. Growth and development of structures within the acinus largely occurs after birth and there is argument as to whether true alveoli are formed at all in intrauterine life (Emery, 1969a). Sublethal fibroblastic proliferation within the walls of the alveoli (or saccules) may be of little consequence provided it does not interfere with their later remodelling and the development of further alveoli. Musculoelastic thickening of the walls of the respiratory bronchioles might be of more serious significance, as this is a region where further alveoli are due to develop by the process which Emery (1969b) describes as fragmentation of the airway. Emery has indeed pointed out the likely serious significance of lesions affecting this prosess.

Additional factors may be involved in producing the grossly irregular lungs seen in infants with severe pulmonary fibroplasia who survive for a month or more (Stage IV bronchopulmonary dysplasia as described by Northway et al., 1967). In these lungs, many acini have remained almost unventilated due to the impaction of uncleared secretions. Failure of alveolar growth within 
these nonfunctioning acini seems likely to follow, as has been suggested in conditions such as McLeod's syndrome (Reid and Simon, 1962) and bronchial atresia (Simon and Reid, 1963). This, combined with some degree of overexpansion, or overgrowth, in the well-ventilated acini (described as centrilobular emphysema by Rosan and Lauweryns, 1970) would account for the characteristic distortion of lung architecture.

Prevention of pulmonary fibroplasia. If, as is suggested here, pulmonary fibroplasia is a result of oxygen toxicity in which the effects may be enhanced by mechanical ventilation of an abnormal lung, prevention of the condition demands reduction of inspired oxygen concentration to below $60 \%$ and minimal use of artificial ventilation.

No case of severe pulmonary fibroplasia has been seen in the Neonatal Unit for the past 2 years, despite the use of artificial ventilation to treat many infants with HMD. It is difficult to attribute this to any one alteration in management. The improvement in humidification mentioned above may have allowed both earlier weaning from the ventilator and also a shorter time in high concentrations of oxygen. All staff working in the unit have become well aware of the possible hazards of high inspired oxygen concentrations, while the performance of a controlled clinical trial of the limitation of inspired oxygen concentration to $40 \%$ in infants with respiratory distress has probably influenced attitudes to oxygen therapy in all newborn babies.

Finally, it must be mentioned that the recent introduction of continuous positive airway pressure (CPAP) in the treatment of newborn infants with respiratory distress (Gregory et al., 1971) offers a means by which we believe the dual aims of limiting inspired oxygen concentration to below $60 \%$ and keeping artificial ventilation to a minimum, may often be achieved.

This work was performed while D. J. Girling was Percy J. Neate Research Fellow of the Worshipful Company of Clothworkers. We are indebted to the MRC for a grant for technical assistance to J. S. Wiggles- worth, and to Professor J. P. M. Tizard and Dr. J. W. Scopes for their advice and encouragement.

\section{REFERENCES}

Barnes, N. D., Glover, W. J., Hull, D., and Milner, A. D. (1969). Effects of prolonged positive-pressure ventilation in infancy. Lancet, 2, 1096.

Becker, M. J., and Koppe, J. G. (1969). Pulmonary structural changes in neonatal hyaline membrane disease treated with high pressure artificial respiration. Thorax, 24, 689.

Capers, T. H. (1961). Pulmonary hyaline membrane formation in the adult. American fournal of Medicine, 31, 701.

deLemos, R., Wolfsdorf, J., Nachman, R., Block, A. J., Leiby, G., $\vec{\odot}$ Wilkinson, H. A., Allen, T., Haller, J. A., Morgan, W., and Avery, M. E. (1969). Lung injury from oxygen in lambs: the role of artificial ventilation. Anesthesiology, 30, 609.

Emery, J. (1969a). The Anatomy of the Developing Lung, p. 8. Heinemann, London.

Emery, J. (1969b). The Anatomy of the Developing Lung, p. 56. Heinemann, London.

Grausz, J. P., Watt, N. L., and Becket, A. J. (1967). A new positivepressure respirator for newborns. Lancet, 2, 499.

Gregory, G. A., Kitterman, J. A., Phibbs, R. H., Tooley, W. H., and Hamilton, W. K. (1971). Treatment of the idiopathic is respiratory-distress syndrome with continuous positive airway pressure. New England fournal of Medicine, 284, 1333.

Hawker, J. M., Reynolds, E. O. R., and Taghizadeh, A. (1967). 을 Pulmonary surface tension and pathological changes in infants dying after respirator treatment for severe hyaline membrane disease. Lancet, 2, 75.

Nash, G., Blennerhassett, J. B., and Pontoppidan, H. (1967), Pulmonary lesions associated with oxygen therapy and artificial ventilation. New England fournal of Medicine, 276, 368.

Northway, W. H., Rosan, R. C., and Porter, D. Y. (1967). Pulmonary disease following respirator therapy of hyaline-membrane disease: bronchopulmonary dysplasia. New England Fournal of Medicine, 276, 357.

Pusey, V. A., Macpherson, R. I., and Chernick, V. (1969). Pulmonary fibroplasia following prolonged artificial ventilation of newborn infants. Canadian Medical Association fournal, $100,451$.

Reid, L., and Simon, G. (1962). Unilateral lung transradiancy. Thorax, 17, 230.

Robertson, B., Tunell, R., and Rudhe, U. (1964). Late stages of pulmonary hyaline membranes of the newborn. Acta Paediatrica, 53, 433.

Robinson, F. R., Harper, D. T., Jr., Thomas, A. A., and Kaplan H. P. (1967). Proliferative pulmonary lesions in monkeys exposed to high concentrations of oxygen. Aerospace Medicine, $38,481$.

Rosan, R. C., and Lauweryns, J. M. (1970). Clinicopathological aspects of oxygen toxicity of the newborn human and animal (bronchopulmonary dysplasia). fournal of Pathology, 101, Pxiii.

Shanklin, D. R. (1969). A general theory of oxygen toxicity in man. Perspectives in Biology and Medicine, 13, 80 .

Simon, G., and Reid, L. (1963). Atresia of an apical bronchus of the left upper lobe: report of three cases. British fournal of Diseases of the Chest, 57, 126.

Correspondence to Dr. J. S. Wigglesworth, The Neonatal Research Unit, Institute of Child Health, Hammersmith Hospital, London W12. 